\title{
Medicina regenerativa en andrologia: Ingeniería Tisular y terapia génica como posibles opciones de tratamiento para las deformaciones peneanas y la disfunción eréctil
}

\author{
Schultheiss D*, Jonas U. \\ Servicio de Urología y Urología Pediátrica. Red de Ingeniería Tisular. Facultad de Medicina de Hannover. \\ Alemania.
}

Actas Urol Esp. 2006;30(8):801-811

\begin{abstract}
RESUMEN
MEDICINA REGENERATIVA EN ANDROLOGÍA: INGENIERÍA TISULAR Y TERAPIA GÉNICA COMO POSIBLES OPCIONES DE TRATAMIENTO PARA LAS DEFORMACIONES PENEANAS Y LA DISFUNCIÓN ERÉCTIL

Se están investigando la ingeniería tisular y la terapia génica en estudios en animales para reconstruir el tejido peneano o tratar la disfunción eréctil. En esta revisión se pretende examinar estos esfuerzos experimentales de los últimos años y se intenta ofrecer una breve introducción a la metodología básica de estas nuevas técnicas del campo de la medicina regenerativa.

Palabras clave: Andrología. Deformación peneana. Disfunción eréctil. Ingeniería tisular. Terapia génica.
\end{abstract}

\section{ABSTRACT}

REGENERATIVE MEDICINE IN ANDROLOGY: TISSUE ENGINEERING AND GENE THERAPY AS POTENTIAL TREATMENT OPTIONS FOR PENILE DEFORMATIONS AND ERECTILE DYSFUNCTION

Tissue engineering and gene therapy are currently investigated in animal studies for reconstructing penile tissue or treating erectile dysfunction. This review aims to ecamine these experimental efforts from the last years and tries to give a brief introduction to the basic methodology of these new techniques from the field of regenerative medicine.

Keywords: Andrology. Penile deformation. Erectile dysfunction. Tissue engineering. Gene therapy.

$\mathrm{L}$ a medicina regenerativa es una nueva y prometedora área de esfuerzo investigador, definida recientemente al conectarse los campos de la ingeniería tisular, la investigación en células troncales, la terapia génica y la clonación terapéutica $^{1,2}$. A medida que vayamos conociendo los procesos de reparación del organismo a nivel celular y genético, podremos avanzar hacia el objetivo de mantener o reconstruir nuestros organismos con una función normal.

Para reconstruir las estructuras peneanas y tratar la disfunción eréctil (DE), los avances recientes en la ingeniería tisular y en la terapia génica tienen un interés especial para los andró- logos. En este momento, el uso de células troncales y la aplicación de la clonación terapéutica no desempeñan un papel importante en estos aspectos de la andrología.

Con la ingeniería tisular se pretende la sustitución de tejidos $\mathrm{u}$ órganos completos, mientras que la terapia génica trabaja a nivel celular con la estructura tisular básica del órgano todavía intacta, pero con determinados mecanismos celulares funcionales alterados. En general, pueden emplearse ambas técnicas en combinación para aumentar al máximo el efecto terapéutico, como demostrarán algunos ejemplos de células sometidas a ingeniería genética en esta revisión. 


\section{INGENIERÍA TISULAR DE ESTRUCTURAS PENEANAS}

La indicación de procedimientos de faloplastia se produce por malformaciones congénitas graves, pérdida del tejido peneano por tumores malignos, traumatismos $\mathrm{u}$ otras enfermedades $\mathrm{y}$ la disforia sexual. En estos casos, puede realizarse cirugía reconstructiva usando tejido autólogo en forma de técnicas de transferencia microquirúrgicas y de tejido libre, p. ej., colgajos del antebrazo radial o del peroné. Para facilitar la erección del neofalo, puede valorarse el uso de implantes peneanos semirrígidos o inflables o de un hueso autólogo, como un colgajo osteocutáneo ${ }^{3,4}$.

Existen diversos procedimientos quirúrgicos de colgajos cutáneos genitales o transferencia de tejido extragenital autólogo para la reconstrucción de la uretra masculina, especialmente en la hipospadias grave y en las estenosis uretrales amplias. Durante los últimos años, se han dedicado grandes esfuerzos a las matrices de colágeno acelular o a los andamiajes resembrados con células uroteliales para sustituir los defectos de la uretra ${ }^{5}$. Como algunas de las técnicas en desarrollo parecen prometedoras y como hay un amplio espectro de indicaciones de tales procedimientos, la ingeniería tisular de la uretra probablemente se convertirá en una de las primeras aplicaciones muy usadas de la medicina regenerativa para la urología en el futuro.

La piel obtenida mediante ingeniería tisular ya ha entrado en la práctica clínica para el tratamiento de las úlceras crónicas o las quemaduras amplias y puede considerarse como alternativa para el patrón de referencia de autoinjertos de grosor parcial en estas indicaciones ${ }^{6}$. En teoria, estos métodos podrían ser beneficiosos para pacientes con pérdida cutánea intensa después de una gangrena de Fournier, pero normalmente se trata de pacientes con múltiples enfermedades que no son candidatos muy idóneos para procedimientos reconstructivos sofisticados.

Como esta revisión está dedicada a la andrología, se centrará sólo en el trabajo experimental relacionado con la ingeniería tisular de las estructuras directamente implicadas en la erección del pene, esto es, los cuerpos cavernosos y los nervios cavernosos.

\section{Cuerpo cavernoso funcional}

Aunque consta sólo de dos tipos celulares funcionales importantes, esto es, las células del músculo liso y las células endoteliales, el cuerpo cavernoso tiene una compleja anatomía microscópica, de una red parecida a una esponja de espacios sinusoidales. Esta estructura se apoya en tejido conjuntivo y está vinculada a un sistema vascular y neuronal para facilitar y controlar el flujo sanguíneo y, a través de él, la erección. En conjunto, esto hace que sea una tarea dificil diseñar el cuerpo cavernoso completo o incluso una parte del mismo.

Se ha establecido el aislamiento de células primarias del cuerpo cavernoso en muchos laboratorios que realizan experimentos basados en cultivos celulares sobre la fisiología de la erección y la fisiopatología de la disfunción eréctil u otros trastornos peneanos, p. ej. la enfermedad de Peyronie ${ }^{6 b i s}$. Hasta el momento, sólo el grupo de Atala de Boston ha utilizado estas células para resembrarlas en diferentes matrices al objeto de reconstruir el tejido cavernoso funcional.

En los primeros estudios, se sembraron células de músculo liso cavernoso humanas $\operatorname{solas}^{7} \mathrm{o}$ en cocultivo con células endoteliales ${ }^{8}$ en mallas de polímeros de ácido poliglicólico biodegradables de una porosidad mayor del $95 \%$ y se implantaron subcutáneamente en ratones atímicos. Se encontraron histológicamente capas múltiples cada vez mayores de células de músculo liso intactas en cualquier momento después de la implantación creciendo a lo largo de la superficie del polímero con obvia degradación del propio polímero después de 24 días. Entre 28 y 42 días después de la implantación, se observó una construcción tisular bien organizada con vasculatura natural penetrante. Se postuló que este efecto era más pronunciado en el grupo con células endoteliales sembradas adicionalmente y que este cocultivo podría ser necesario para crear tejido cavernoso bien vascularizado. En los polímeros de control no resembrados, no hubo pruebas de tal formación de tejidos.

Estos resultados se confirmaron con células de músculo liso de los cuerpos y células endoteliales humanas sembradas en matrices acelulares procesadas de cuerpos cavernosos de conejos donantes ${ }^{9}$. Nuevamente, estos injertos se implan- 
taron subcutáneamente en ratones atímicos, que sirvieron como "incubadores de células o tejidos vivos". Después de la explantación, sólo los injertos resembrados mostraron contracción del tejido ante la estimulación con campos eléctricos en los estudios de baños de órganos.

En la siguiente serie de experimentos del mismo laboratorio, se descelularizaron segmentos transversales completos de $0,7 \mathrm{~cm}$ de longitud de cuerpos cavernosos de conejo después de la escisión y se usaron como matriz de partida acelular para repoblar posteriormente con células de músculo liso cavernoso y endoteliales autólogas de $\operatorname{conejos}^{10}$. Estas construcciones de ingeniería tisular se interpusieron luego en los cuerpos cavernosos de los animales de los cuales se habían recogido las células respectivas. El resultado se evaluó mediante cavernosonografia, presión intracavernosa durante la erección artificial (cavernosonometría), comportamiento en cuanto a emparejamientos y eyaculación de esperma así como mediante análisis específicos de células con inmunohistoquímica y Western blot para la sintasa del óxido nítrico en el área del injerto después de 3 y 6 meses y se compararon con animales control que recibieron implantes no resembrados. Según este estudio, los animales con segmentos de cuerpos cavernosos de ingeniería tisular mostraron resultados funcionales y morfológicos mucho mejores.

Actualmente, estos investigadores están tratando de diseñar una pieza cilíndrica de mayor tamaño de tejido del cuerpo cavernoso para abordar el problema de la reconstrucción fálica. Queda la cuestión de cómo se implantará funcionalmente luego este tejido de ingeniería, ya sea como injerto parcial en un cuerpo cavernoso fibrótico o rudimentario o como un cilindro corporal completamente nuevo. Conectar dichos injertos a la circulación sanguínea y la inervación autonómica funcionales son otros objetivos a alcanzar $^{11,12}$.

Otro abordaje para recuperar la función eréctil mediante tratamiento basado en células podría ser la inyección de células funcionales en el cuerpo cavernoso, p. ej., en casos de disfunción endotelial intensa o disminución de las células de músculo liso. Esto ha sido sugerido e investigado experimentalmente en primer lugar para los tras- plantes de células endoteliales realizados por Wessells de Tucson ${ }^{13}$. Se inyectaron células endoteliales autólogas marcadas fluorescentemente en el cuerpo cavernoso de la rata. Después de dos días, se seguían viendo acúmulos de células dentro de los sinusoides corporales centrales, mientras que después de una y dos semanas, sólo se detectaron células restantes periféricamente en los sinusoides detrás de la túnica albugínea. Aunque esta técnica podría valorarse para la reparación directa del endotelio lesionado de los cuerpos cavernosos, este tipo de tratamiento basado en células para la disfunción eréctil, ya sea con células endoteliales o del músculo liso, sólo parece prometedor cuando se combina con la manipulación celular mediante terapia génica antes de la transferencia celular, esto es células sometidas a ingeniería genética, como se comentará a continuación ${ }^{14-16}$.

\section{Bastones cartilaginosos peneanos}

Un planteamiento más sencillo para restaurar la rigidez peneana sería la ingeniería tisular de bastones de cartílagos como alternativa al estándar clínico actual de los implantes peneanos aloplásticos semirrígidos o inflables. La factibilidad inicial de crear un bastón cartilaginoso resembrando polímeros de ácido poliglicólico cilíndrico con condrocitos bovinos e implantación subcutánea en ratones atímicos fue introducida por el laboratorio de Boston ya ocupado en la ingeniería tisular de tejido funcional de los cuerpos cavernosos mencionado antes ${ }^{17}$. En un segundo intento, se implantaron bastones comparables, resembrados con condrocitos autólogos de oídos de conejo, en los cuerpos cavernosos de los animales respectivos y se evaluaron histológicamente después de 1 a 6 meses $^{18}$. No hubo pruebas de erosión o infección y los animales pudieron copular e impregnar a sus parejas hembra sin problemas. Finalmente, se compararon las propiedades mecánicas de tales implantes de cartílago obtenidos mediante ingeniería genérica $(1,2 \mathrm{~cm}$ de diámetro y $6,0 \mathrm{~cm}$ de longitud) repoblados con células humanas e implantados en ratones atímicos con los de implantes de silicona disponibles comercialmente $^{19}$. Este estudio demostró que los bastones tratados mediante ingeniería eran flexibles, elásticos y estables para soportar altos gra- 
dos de fuerzas compresivas, comparables a las propiedades de los implantes de silicona estándar.

Aunque este concepto podría ser adoptado fácilmente para estudios clínicos, determinadas cuestiones relativas a las interacciones tisulares a largo plazo y la estabilidad de dichos bastones tienen que contestarse antes. Que los pacientes acepten y aprueben dicha solución respecto a los implantes inflables estándar, es otro asunto. Además, un vistazo a la historia de la medicina revela un método similar pero mucho más fácil y menos costoso para los implantes de cartílagos autólogos. El cirujano ruso Nikolaj A. Bogoraz fue el primero en incorporar el cartílago de costilla autólogo en un neofalo reconstruido en los años 30 para facilitar la erección ${ }^{20}$. Durante los años siguientes, incluso implantó cartílago respectivo entre los cuerpos cavernosos de penes anatómicamente intactos de pacientes que padecían $\mathrm{DE}^{21}$. El uso de cartílago de costilla autólogo para la reconstrucción peneana se ha mantenido hasta el presente y recientemente se sugirió como paso esencial en un procedimiento verdadero de alargamiento del pene ${ }^{22}$.

\section{Túnica albugínea}

Se han usado diversos materiales como injertos para sustitución de la túnica albuginea del pene principalmente después de la incisión o resección de placas en la cirugía de la enfermedad de Peyronie. Mientras que los injertos autólogos viables de venas o dermis son los más usados en la rutina clínica hoy en día, se han evaluado otros materiales biológicos en experimentos en animales y en estudios humanos como posibles soluciones listas para usar ${ }^{23}$. Entre ellos están los materiales biológicos descelularizados, como la submucosa del intestino delgado (SID), la dermis, el pericardio cadavérico, la lámina de colágeno recubierto con pegamento tisular ${ }^{24}$ o la matriz de túnica albugínea descelularizada ${ }^{25}$. Después de los primeros resultados prometedores con SID, un grupo ha comunicado recientemente una tasa significativa de resultados desfavorables en pacientes pediátricos tratados con SID acelular para injertos cavernosos ${ }^{26}$. La falta inicial de células viables dentro de este material de injerto podría explicar estos resultados.
En un reciente informe de nuestro laboratorio, se sugirió un parche realizado mediante ingeniería tisular y se estableció un sistema de biorreactor mecánico para crear injertos de túnica estables a partir de matriz acelular, p. ej., submucosa del intestino delgado y fibroblastos autólogos resembrados ${ }^{27}$. No se ha realizado hasta el momento una evaluación experimental en animales y no queda claro si los fibroblastos autólogos cultivados tomados de otra área del cuerpo del receptor, p. ej, de pequeñas biopsias cutáneas, contrarrestarán o incluso potenciarán una fibrosis no controlada en el área del injerto.

\section{Nervios cavernosos}

La prostatectomía radical para el cáncer de próstata es un procedimiento urológico frecuente y a menudo implica daños mecánicos o incluso resección amplia de los nervios cavernosos, que conduce a disminución o pérdida de la función eréctil postoperatoria ${ }^{28}$. En aquellos casos en los que la prostatectomía conservadora de nervios es imposible por razones oncológicas, se ha evaluado la reconstrucción quirúrgica con interposición de injerto de nervio sural autólogo durante los últimos años en varios ensayos clínicos ${ }^{29}$. El resultado clínico de estos estudios de injertos nerviosos parece ser menos favorable de lo que se esperaba inicialmente $\mathrm{y}$, aunque fue pionero de este procedimiento en $1991^{30}$, Walsh, de Baltimore, mientras tanto, se ha convertido en un crítico de esta técnica por muchas razones ${ }^{31}$.

No obstante, un interesante estudio piloto experimental realizado por May, en Munich, abrió una nueva vía para la reconstrucción nerviosa mediante ingeniería tisular de nervios cavernosos $^{32}$. Se expandieron en cultivos células de Schwann aisladas de nervios ciáticos de rata y se sembraron en tubos de silicona que se interpusieron microquirúrgicamente en resecciones bilaterales de $5 \mathrm{~mm}$ de nervios cavernosos en ratas. Actuaron como controles una operación falsa, una resección nerviosa sin reconstrucción, una interposición del nervio genitofemoral o una interposición de tubos de silicona vacíos. Los mejores resultados funcionales después de tres meses evaluados por las erecciones visibles y la presión intracavernosa después de estimulación eléctrica se alcanzaron en el grupo que usó tubos 
resembrados con células de Schwann. Los resultados de los autotransplantes genitofemorales fueron desalentadores.

Muy recientemente, el mismo autor ha presentado sus datos ampliados demostrando un resultado incluso mejor del procedimiento cuando las células de Schwann sembradas fueron modificadas genéticamente usando vectores retrovíricos para producir y secretar niveles elevados de factor neurotrófico derivado de una línea celular de glía (GDNF). Esto no sólo se documentó mediante pruebas funcionales, sino también mediante la histología respectiva de los cortes nerviosos ${ }^{33}$.

Estrechamente relacionados con este planteamiento científico están otros estudios en los que se evaluó una mejoría de la recuperación nerviosa en un modelo de aplastamiento o congelación de nervios cavernosos en la rata. Después de un daño nervioso experimental, Lue y sus colaboradores de San Francisco inyectaron factor de crecimiento endotelial vascular (VEGF) y factor neurotrófico obtenido del cerebro (BDNF) inmediatamente o de forma diferida durante un mes en los cuerpos cavernosos de los animales ${ }^{34}$. La evaluación funcional y morfológica después de tres meses demostró una mejoría significativa de la respuesta de la presión intracavernosa a la estimulación del nervio cavernoso y un mayor número de fibras nerviosas teñidas positivamente para la NADPH diaforasa y tirosina hidroxilasa en el grupo tratado respecto al grupo con operación falsa.

En lugar de inyectar directamente el factor neurotrófico, se han realizado también abordajes con proteínas con transferencia génica. $\mathrm{El}$ grupo de San Francisco usó factor neurotrófico derivado del cerebro mediado por el virus asociado a adeno $^{35,36}$ y el equipo de Chancellor de Pittsburgh inyectó supensiones víricas de vector del virus herpes simple que codificaban factor neurotrófico derivado de líneas celulares de glía (GDNF) o factor de crecimiento nervioso (NGF) en los cuerpos cavernosos de ratas para alcanzar el mismo efecto de recuperación del nervio cavernoso ${ }^{37}$.

En conclusión, la investigación básica actual sobre regeneración y reconstrucción del nervio cavernoso es un ejemplo que vincula de forma muy bonita la ingeniería tisular y la terapia génica como las dos técnicas más importantes de medicina regenerativa en el campo de la andrología.

\section{TERAPIA GÉNICA PARA LA DISFUNCIÓN ERÉCTIL}

Hay un amplio campo de investigación actual y muchos estudios en los últimos años han abordado la factibilidad de la terapia génica para el tratamiento de la disfunción eréctil. Como la relajación de las células del músculo liso es el mecanismo fundamental de la erección, todas las moléculas y enzimas implicadas en la transducción de la señal para aumentar la relajación o inhibir la contracción de células de músculo liso corporales son posibles dianas para la transferencia génica al cuerpo cavernoso.

Esta revisión ofrece una introducción a los principios generales de la terapia génica y una perspectiva sistemática breve sobre los planteamientos actuales usando estas técnicas para el tratamiento de la disfunción eréctil. Para cualquier otra información, hay revisiones excelentes y más detalladas de los investigadores principales en Nueva Orleáns y Nueva York que son muy recomendables ${ }^{38,39}$.

\section{Aspectos generales de la terapia génica}

El objetivo común de la terapia génica es introducir material genético nuevo o perdido en las células del tejido diana para recuperar la función del órgano. Inicialmente, la terapia génica abordaba enfermedades que tenían un componente genético subyacente, intentando reparar este defecto genético primario. Mientras tanto, las indicaciones de la terapia génica, al menos en teoría, se han ampliado a casi todas las enfermedades en las que se identifica un gen terapéutico que es capaz de restaurar o apoyar una función celular perdida o reducida.

El pene, o para ser más precisos, el cuerpo cavernoso como principal órgano efector para la erección, es una diana perfecta para la terapia génica. Tiene una localización externa anatómicamente favorable con un sistema de circulación sanguínea fundamentalmente separado, bien adecuado para las inyecciones periódicas de material genético específico. Recientemente, se ha sugerido un cañón génico sin aguja para la administración transcutánea con alta presión de ADN de plásmido al pene ${ }^{40}$. La compresión temporal adicional de la raíz del pene evita en gran medida la entrada precoz de los productos géni- 
cos en la circulación sistémica. Esto reduce al mínimo los efectos secundarios sistémicos indeseados y produce una excelente captación en las células endoteliales y de músculo liso del cuerpo cavernoso. Además, en el cuerpo cavernoso podría ser suficiente transfectar sólo un pequeño número de células del cuerpo debido a las uniones intercelulares comunicantes que facilitan una respuesta colectiva tisular sincitial, p. ej., de relajación de las células de músculo liso $38,39,41$.

\section{Métodos de transferencia génica}

Se necesita un vehículo o vector para transferir la información genética en forma de $\mathrm{ADN}$ o ARN a las células diana. El vector ideal proporcionaría las ventajas de una transducción eficiente a muchas células y expresión transgénica estable y de larga duración después de la transferencia. Por otro lado, las infecciones, las reacciones inmunógenas y la mutagenia de la célula huésped son posibles riesgos de la terapia génica. Hasta el momento, no hay un vector único que satisfaga todas estas demandas al mismo tiempo. Los vectores aplicados para la terapia génica se dividen en vectores no víricos (ADN desnudo, ADN de plásmidos y liposomas), los vectores víricos (retrovirus, adenovirus y virus asociado a adeno) y las células sometidas a ingeniería genética como vehículos ${ }^{38}$.

\section{Vectores no víricos}

Son una forma muy segura de terapia génica y no producen respuestas inmunitarias ni inflamatorias en el huésped. Por otro lado, la eficiencia de transferencia génica es muy baja $(<1 \%$ para el ADN desnudo) y la expresión es sólo transitoria. Los liposomas pueden aumentar la entrada intracelular del material genético potenciando la fusión con la membrana plasmática.

\section{Vectores víricos}

La alta eficiencia de transferencia génica es característica de todos los vectores víricos. En los vectores retrovíricos, todos los genes víricos se eliminan y sustituyen por información de genes terapéuticos, pero estos vectores sólo pueden integrarse en el ADN de células en división, por lo que conllevan un riesgo aumentado de mutagénesis. Como las células cavernosas del pene no proliferan, los retrovirus no son muy adecuados para el tratamiento de la DE. A diferencia de los retrovirus, los adenovirus y los virus asociados a los adeno también transfectan suficientemente las células diana que no se están dividiendo y pueden producirse con títulos muy altos. La posible expresión de proteínas adenovíricas en la célula huésped infectada es responsable de la reacción inmunitaria e inflamatoria. Este efecto está reducido en los vectores adenovirus de segunda generación, también denominados vectores adenovirus "sin entrañas" (gutless) dependientes de colaboradores, en los que los genes víricos están borrados.

Células sometidas a ingeniería genética (esto es, terapia génica basada en células)

Se recogen células específicas del tejido diana, p. ej., células endoteliales o de músculo liso cavernosas, del paciente y se expanden en cultivo. Los genes que codifican las proteínas terapéuticas se transfieren después a estas células mediante vectores no víricos o víricos $\mathrm{y}$ las células autólogas modificadas genéticamente se reintroducen finalmente en el tejido concreto del cuerpo del huésped. Una vez que las células están integradas de nuevo en el tejido satisfactoriamente, esta forma de transferencia génica mediada por células es una opción segura y eficaz.

Dianas para la terapia génica de la disfunción eréctil

A diferencia de la farmacoterapia oral o intracavernosa establecida, la terapia génica tiene la capacidad de alcanzar una restauración duradera de la función del órgano y de esta forma, curar la DE. Así, el paciente podría volver a una vida sexual normal sin necesidad de una medicación a demanda. La duración del efecto terapéutico del gen es el punto crítico en la mayoría de los estudios y la inyección repetida del vehículo o vector codificador del gen parece inevitable en este momento 38,39 .

El pasaje siguiente resume brevemente los esfuerzos actuales de los estudios preclínicos en animales para la terapia génica de la DE. Casi todos estos estudios se realizaron en el modelo de rata anciana o diabética y el éxito postratamiento 
se evaluó fundamentalmente midiendo el aumento del producto génico o sus metabolitos y mediante la respuesta funcional de la presión intracavernosa a la estimulación eléctrica de los nervios. Se comentan los estudios ordenados por el producto génico diana respectivo influido por la transferencia génica.

\section{Sintasa del ácido nítrico (NOS)}

La vía de óxido nítrico (NO)/guanilato ciclasa/cGMP de la erección fue una de las primeras dianas de la terapia génica al introducir NOS en el cuerpo cavernoso. Hay tres isoformas de NOS de importancia en el pene: la NOS neuronal (nNOS), la NOS endotelial (eNOS) y la NOS inducible (iNOS). Estas enzimas sintetizan óxido nítrico (NO), un mediador importante para la relajación de las células del músculo liso, a partir de Larginina y oxígeno.

Garban et al. de Los Angeles, fueron los primeros en usar ADN complementario (ADNc) desnudo codificando iNOS peneano de rata (PnNOS) para la transfección experimental ${ }^{42}$; Rehman et al. realizaron una transferencia de ADNc similar a partir de nNOS $^{43}$. Más adelante, el primer grupo tuvo también éxito con la transferencia mediada por adenovirus "sin entrañas" dependientes de colaboradores, de PnNOS con un efecto que duró al menos 18 días $^{44}$. Recientemente, introdujeron también el concepto de terapia génica de tratamiento antisentido (véase más adelante) para la inhibición de la expresión génica de PIN (inhibidor proteínico del ADNc de NOS). El PIN es una proteína que inhibe a la nNOS uniéndose a su dominio N-terminal codificado por el exón 2 y mediante este mecanismo, contrarresta la erección ${ }^{45}$.

Bivalacqua y Hellstrom de Nueva Orleáns se estaban centrando en la eficacia de la transfección de eNOS mediado por vectores adenovíricos en el cuerpo cavernoso de ratas ancianas ${ }^{46,47} \mathrm{y}$ diabéticas ${ }^{48}$. El efecto proeréctil de la transferencia del gen de eNOS se midió mediante aumento de la presión intracavernosa después de 5 días en los animales ancianos y volvió a los valores pretratamiento después de 7 y 10 días en los diabéticos. La misma institución comunicó sus esfuerzos para una terapia génica basada en células troncales consistente en la transferencia del gen de nNOS mediada por adenovirus a células estromales de médula expandidas ex vivo, también denominadas células troncales mesenquimatosas obtenidas de médula ósea ${ }^{15}$. Estas células troncales adultas transfectadas se inyectaron después en el pene y se midió un aumento de la expresión de eNOS y de la respuesta eréctil en este grupo después de 7 días.

Chancellor, de Pittsburgh, realizó otro planteamiento basado en células usando mioblas$\operatorname{tos}^{14,16}$. La transferencia génica de iNOS mediada por células con mioblastos al cuerpo cavernoso se comparó con el resultado de la transfección basada en plásmidos y adenovirus y mostró mejores resultados funcionales dos días después de la inyección.

Las preocupaciones generales con la terapia génica con NOS son la duración relativamente corta del efecto fisiológico, los efectos secundarios desconocidos de la sobreexpresión a largo plazo de NO y finalmente, la posibilidad de priapismo $^{39}$.

\section{Canales de potasio}

El grupo de Nueva York de Christ y Melman ha sido pionero en investigación básica sobre la función del canal de $\mathrm{K}$ y la unión intercelular comunicante en tejido cavernoso, revelando la estrecha relación de la actividad del canal K, el flujo de calcio transmembranoso a través de los canales de calcio dependientes del voltaje y el tono del músculo liso de los cuerpos cavernosos ${ }^{49}$. Uno de sus primeros planteamientos terapéuticos génicos en 1998 empleó ya hSlo/ADNc, una secuencia que codificaba el canal $\mathrm{K}$ maxi sensible al calcio de gran conductancia ${ }^{50}$ y el estudio más reciente siguiendo la función eréctil en ratas ancianas durante un periodo de hasta 6 meses después de la transfección con diferentes concentraciones del vector plásmido hSlo/ADNc mostraron un resultado muy favorable ${ }^{51}$. Hasta el momento, esta es la mayor duración de cualquier efecto de la terapia génica para la $\mathrm{DE}$ observada, aunque se usó un vector no vírico y por eso, teóricamente menos eficiente. Este planteamiento parece muy prometedor y seguro para la aplicación clínica y recientemente ha obtenido la aprobación de la FDA para ensayos clínicos de fase $\mathrm{I}^{39,51 \mathrm{bis} \text {. }}$ 
Este grupo está investigando también la transferencia génica de otros canales $\mathrm{K}^{49} \mathrm{y}$ adicionalmente, desde Corea se comunicó un estudio sobre la transferencia génica ex vivo de canal de potasio sensible a ATP (KATP) a células de músculo liso del cuerpo cavernoso cultivadas ${ }^{52}$.

\section{Sistema Rho/Rho cinasa}

Mediante la fosforilación de la subunidad reguladora de la fosfatasa de cadena ligera de la miosina, la Rho-cinasa aumenta la sensibilización al calcio, potenciando así la contractilidad del músculo liso del cuerpo cavernoso y la flacidez peneana. Se ha identificado el RhoA como un activador de la Rho-cinasa, mientras que el mutante doble negativo RhoA actúa como inhibidor de RhoA, contrarrestando así la Rho-cinasa y teniendo un efecto proeréctil. En un experimento multiinstitucional se demostró que la transfección mediante virus asociados a los adenos del cuerpo cavernoso de la rata con este mutante de RhoA potencia la función eréctil durante al menos siete dias ${ }^{53}$.

Péptido relacionado con el gen de la calcitonina (CGRP)

El CGRP es conocido como un potente vasodilatador en varios lechos vasculares periféricos del cuerpo incluido el pene y se ha investigado para la terapia de inyección intracavernosa de la DE en el pasado. Bivalacqua y sus colaboradores de Nueva Orleáns y Baltimore realizaron transferencia génica mediada por adenovirus de preproCGRP a los penes de ratas ancianas, en las que se sabe que el CGRP está regulado a la baja ${ }^{54}$. Cinco días después de la inyección de adenovirus, el contenido de proteína CGRP, ARNm de la CGRP y AMP así como la respuesta funcional eréctil fueron mayores en los animales ancianos transfectados con CGRP en comparación con los controles.

\section{Superóxido dismutasa (SOD)}

El mismo grupo de investigadores abordaron el aumento del estrés oxidativo en animales ancianos como posible diana para la terapia génica $^{55}$. El anión superóxido es uno de los radicales $\mathrm{O}_{2}$ responsables de la disfunción vascular en la hipertensión, la aterosclerosis, la diabetes melli- tus y el envejecimiento normal. La antioxidante SOD es importante para la protección extra e intracelular frente a estos radicales. La actividad de la SOD extracelular se elevó mediante la transferencia de genes adenovíricos, conduciendo a una disminución del aumento de los niveles de GMPc y mejor respuesta eréctil funcional.

Factores de crecimiento y factores neurotróficos Lue y sus colaboradores de San Francisco, evaluaron la transferencia génica mediada por virus asociados a los adeno con factor de crecimiento endotelial vascular (VEGF) en un modelo de castración en la rata ${ }^{56}$. Ratas castradas desarrollan DE venooclusiva, que puede revertirse mediante tratamiento de sustitución androgénica o por el efecto angiogénico de la inyección de VEGF intracavernosa o sistémica. En este estudio se compararon estas dos opciones con la terapia génica del VEGF y se demostró que los tres produjeron una mejor función eréctil. El grupo de Shabsigh de Nueva York publicó los primeros resultados con transfección del plásmido con VEGF al cuerpo cavernoso ${ }^{57}$.

Se sabe que el factor de crecimiento de tipo insulínico (IGF) 1 desempeña un papel en la función eréctil. En un estudio preliminar realizado en Corea se investigó la transfección de las células del músculo liso cavernoso cultivadas con $\mathrm{ADNc}$ del IGF-1 in vitro y la transfección in vivo del cuerpo cavernoso con el complejo liposómico ADNpc/IGF$1^{58}$. Mientras que las células cultivadas transfectadas mostraron sobreexpresión de ARNm y proteína IGF-1, la transferencia del gen in vivo no produjo mejora de la función eréctil después de 4 semanas.

Se han abordado los ensayos respectivos con terapia génica del factor neurotrófico por encima en el capítulo sobre ingeniería tisular del cuerpo cavernoso $^{35-37}$.

\section{Oligonucleótidos antisentido}

Se trata de un concepto de tratamiento prometedor empleado en oncología ${ }^{59,60}$. Los oligonucleótidos antisensido son moléculas cortas modificadas de $\mathrm{ADN}$ o ARN diseñadas para unirse selectivamente al ARN mensajero en las células diana y de esta forma inhibir la síntesis de la proteína codificada. Hasta el momento, se han comunicado dos estudios usando este concepto para la terapia 
génica de la DE. La inhibición antisentido de la expresión génica del PIN (inhibidor proteínico del ADNc del NOS), una proteína que inhibe la síntesis de nNOS, ya se mencionó antes ${ }^{45}$. Un grupo de China sugirió el uso de oligonucleótidos antisentido dirigidos contra el ARNm del PDE Visoform y así impedir la traducción de la enzima ${ }^{61}$.

\section{CONCLUSIONES}

Esta revisión ha puesto de manifiesto los objetivos y los límites de la ingeniería tisular y la terapia génica para la reconstrucción del pene y la disfunción eréctil. Aunque algunos de los intentos citados parecen viables para más investigación en un contexto clínico dentro de los próximos años, la mayoría de ellos todavía pertenecen al campo de la investigación básica y no entrarán en el campo clínico dentro de la próxima década o más tarde.

La ingeniería tisular de las estructuras aisladas tanto eréctiles (¡nervios cavernosos!) como peneanas (¡bastones cartilaginosos!) está al alcance de la mano, pero la reconstrucción de todas las estructuras tisulares del pene a la vez y la integración del neoórgano en la circulación sanguínea sistémica y el control neuronal sigue planteando muchas cuestiones no resueltas.

A diferencia de su uso en oncología, la aplicación de la terapia génica en andrología precisa un mayor nivel de seguridad y más conocimientos sobre vectores seguros y eficaces para la transferencia de genes. No obstante, un equipo de investigadores está esperando la aprobación por la FDA para los ensayos clínicos de fase $\mathrm{I}^{39}$.

Al tratar con estas técnicas tan sofisticadas, experimentamos muchas sinergias clínicas y científicas entre la andrología y otras especialidades, especialmente la medicina interna. La disfunción eréctil (DE) se ha convertido en una disfunción endotelial (DE) que podría ser un buen indicador de detección precoz (DP) de la enfermedad cardiovascular general ${ }^{62,63}$. Esto conduce a una situación en la que, p. ej., la terapia génica con eNOS o CGRP se investiga interdisciplinariamente para el tratamiento de la disfunción eréctil y también de la hipertensión pulmonar ${ }^{15,48,64-}$ 66 . Una coincidencia que ya hemos experimentado con el descubrimiento del sildenafil y su reintroducción a la medicina interna más tarde para la misma indicación pulmonar ${ }^{67,68}$.

\section{REFERENCIAS}

1. Atala A. Regenerative medicine and urology. BJU Int. 2003;92(Suppl 1):58-67.

2. Cross WR, Thomas DF, Southgate J. Tissue engineering and stem cell research in urology. BJU Int. 2003;92(2): 165-171.

3. Ninkovic M, Dabernig W. Flap technology for reconstructions of urogenital organs. Curr Opin Urol. 2003; 13(6):483-488.

4. Sievert KD. Vaginal and penile reconstruction. Curr Opin Urol. 2003;13(6):489-494.

5. Atala A. Experimental and clinical experience with tissue engineering techniques for urethral reconstruction. Urol Clin North Am. 2002;29(2):485-492, ix.

6. Bannasch H, Fohn M, Unterberg T, Bach AD, Weyand B, Stark GB. Skin tissue engineering. Clin Plast Surg. 2003;30(4):573-579.

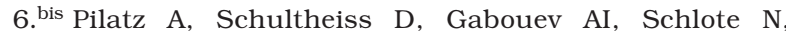
Mertsching H, Jonas U, et al. Isolation of primary endothelial and stromal cell cultures of the corpus cavernosum penis for basic research and tissue engineering. Eur Urol. 2005 May;47(5):710-718; discussion 718-719.

7. Kershen RT, Yoo JJ, Moreland RB, Krane RJ, Atala A. Reconstitution of human corpus cavernosum smooth muscle in vitro and in vivo. Tissue Eng. 2002;8(3):515524.

8. Park HJ, Yoo JJ, Kershen RT, Moreland R, Atala A. Reconstitution of human corporal smooth muscle and endothelial cells in vivo. J Urol. 1999;162(3 Pt 2):11061109.

9. Falke G, Yoo JJ, Kwon TG, Moreland R, Atala A. Formation of corporal tissue architecture in vivo using human cavernosal muscle and endothelial cells seeded on collagen matrices. Tissue Eng. 2003;9(5):871-879.

10. Kwon TG, Yoo JJ, Atala A. Autologous penile corpora cavernosa replacement using tissue engineering techniques. J Urol. 2002;168(4):1754-1758.

11. Biers SM, Brading AF. Nerve regeneration: might this be the only solution for functional problems of the urinary tract? Curr Opin Urol. 2003;13(6):495-500.

12. Nomi M, Atala A, Coppi PD, Soker S. Principals of neovascularization for tissue engineering. Mol Aspects Med. 2002;23(6):463-483.

13. Wessells H, Williams SK. Endothelial cell transplantation into the corpus cavernosum: moving towards cell-based gene therapy. J Urol. 1999;162(6):2162-2164.

14. Chancellor MB, Tirney S, Mattes CE, Tzeng E, Birder LA, Kanai AJ, et al. Nitric oxide synthase gene transfer for erectile dysfunction in a rat model. BJU Int. 2003;91(7): 691-696.

15. Deng W, Bivalacqua TJ, Chattergoon NN, Hyman AL, Jeter Jr JR, Kadowitz PJ. Adenoviral gene transfer of eNOS: high-level expression in ex vivo expanded marrow stromal cells. Am J Physiol Cell Physiol. 2003;285(5): C1322-1329.

16. Tirney S, Mattes CE, Yoshimura N, Yokayama T, Ozawa $\mathrm{H}$, Tzeng $\mathrm{E}$, et al. Nitric oxide synthase gene therapy for erectile dysfunction: comparison of plasmid, adenovirus, and adenovirus-transduced myoblast vectors. Mol Urol. 2001;5(1):37-43.

17. Yoo JJ, Lee I, Atala A. Cartilage rods as a potential material for penile reconstruction. J Urol. 1998;160(3 Pt 2): 1164-1168 Discussion 1178. 
18. Yoo JJ, Park HJ, Lee I, Atala A. Autologous engineered cartilage rods for penile reconstruction. J Urol. 1999;162(3II): $1119-1121$.

19. Kim BS, Yoo JJ, Atala A. Engineering of human cartilage rods: potential application for penile prostheses. J Urol. 2002; 168(4 Pt 2):1794-1797.

20. Bogoraz NA. On complete plastic reconstruction of a penis sufficient for coitus in Russian. Soviet Surgery Sovetskaya khirurgiya. 1936;8:303-309.

21. Bogoraz NA. Reconstructive Surgery in Russian. Vol. 2. Moscow: Medgis; 1948.

22. Perovic SV, Djordjevic ML. Penile lengthening. BJU Int 2000;86(9): 1028-1033.

23. Carson CC, Chun JL. Peyronie's disease: surgical management: autologous materials. Int J Impot Res. 2002;14:329335.

24. Lahme S, Gotz T, Bichler KH. Collagen fleece for defect coverage following plaque excision in patients with Peyronie's disease. Eur Urol.2002;41(4):401-405.

25. Wefer J, Schlote N, Sekido N, Sievert KD, Wefer AE, Nunes L, et al. Tunica albuginea acellular matrix graft for penile reconstruction in the rabbit: a model for treating Peyronie's disease. BJU Int. 2002;90:326-331.

26. Soergel TM, Cain MP, Kaefer M, Gitlin J, Casale AJ, Davis MM, et al. Complications of small intestinal submucosa for corporal body grafting for proximal hypospadias. J Urol. 2003;170(4 Pt 2):1577-1578; 1578-1579.

27. D Schultheiss, RR Lorenz, R Meister, M Westphal, AI Gabouev, H Mertsching, et al. Functional tissue engineering of autologous tunica albuginea: a possible graft for Peyronie's disease surgery. Eur Urol. 2004;45(6):781-786.

28. Meuleman EJ, Mulders PF. Erectile function after radical prostatectomy: a review. Eur Urol. 2003;43:95-101 Editorial Comment by F. Montorsi 101-102.

29. Burnett AL. Neuroprotection and nerve grafts in the treatment of neurogenic erectile dysfunction. $J$ Urol. 2003;170:S31-34 Discussion S34. 168 D. Schultheiss / European Urology 46 (2004) 162-169

30. Quinlan DM, Nelson RJ, Walsh PC. Cavernous nerve grafts restore erectile function in denervated rats. $J$ Urol. 1991;145(2):380-383.

31. Walsh PC. Nerve grafts are rarely necessary and are unlikely to improve sexual function in men undergoing anatomic radical prostatectomy. Urology. 2001;57(6):1020-1024.

32. May F, Weidner N, Matiasek K, Caspers C, Mrva T, Vroemen M, et al. Schwann cell seeded guidance tubes restore erectile function after ablation of cavernous nerves in rats. J Urol. 2004 Jul;172(1):374-377.

33. May F, Weidner N, Matiasek K, Vroemen M, Mrva T, Caspers C, et al. Tissue engineering of erectile nerves Urologe A. 2004 Oct;43(10):1242-1248.

34. Hsieh PS, Bochinski DJ, Lin GT, Nunes L, Lin CS, Lue TF. The effect of vascular endothelial growth factor and brainderived neurotrophic factor on cavernosal nerve regeneration in a nervecrush rat model. BJU Int. 2003;92:470-475.

35. Bakircioglu ME, Lin CS, Fan P, Sievert KD, Kan YW, Lue $\mathrm{TF}$. The effect of adeno-associated virus mediated brain derived neurotrophic factor in an animal model of neurogenic impotence. J Urol. 2001;165(6 Pt 1):2103-2109.

36. Gholami SS, Rogers R, Chang J, Ho HC, Grazziottin T, Lin $\mathrm{CS}$, et al. The effect of vascular endothelial growth factor and adenoassociated virus mediated brain derived neurotrophic factor on neurogenic and vasculogenic erectile dysfunction induced by hyperlipidemia. J Urol. 2003;169(4):1577-15781.
37. Kim JH, Bennett NE, Sasaki K, Yoshimura N, Wolfe DP, Goins WF, et al. Neurotrophic factor gene therapy: potential cure for post radical prostatectomy erectile dysfunction. J Urol. 2003;169(Suppl):303-304.

38. Bivalacqua TJ, Hellstrom WJ. Potential application of gene therapy for the treatment of erectile dysfunction. $J$ Androl. 2001;22(2):183-190.

39. Christ GJ. Frontiers in gene therapy for erectile dysfunction. Int J Impot Res. 2003;15(Suppl 5):S33-40.

40. Tyagi P, Chancellor MB, Yoshimura N, Kim JH, Bennett NE, Huang L. Proof of concept of using the bio-bolistic gene transfer (gene gun) to the rat penis. J Urol. 2003; 169(Suppl):307.

41. Christ GJ, Melman A. The application of gene therapy to the treatment of erectile dysfunction. Int J Impot Res. 1998;10(2):111-112.

42. Garban H, Marquez D, Magee T, Moody J, Rajavashisth $\mathrm{T}$, Rodriguez JA, et al. Cloning of rat and human inducible penile nitric oxide synthase. Application for gene therapy of erectile dysfunction. Biol Reprod. 1997;56(4): 954-563.

43. Rehman J, Christ G, Melman A, Werber J, Alyskewycz M, Staerman F, et al. Enhancement of physiologic erectile dysfunction with nitric oxide synthase gene therapy. J Urol. 1997;157(Suppl):201.

44. Magee TR, Ferrini M, Garban HJ, Vernet D, Mitani K, Rajfer J, et al. Gene therapy of erectile dysfunction in the rat with penile neuronal nitric oxide synthase. Biol Reprod. 2002;67(3):1033-1041.

45. Magee T, Davila HH, Ferrini MG, Raijfer J, GonzalezCadavid NF. Gene transfer of antisense PIN (protein inhibitor of NOS cDNA) ameliorates aging-related erectile dysfunction in the rat. J Urol. 2003;169(Suppl):305.

46. Champion $\mathrm{HC}$, Bivalacqua $\mathrm{TJ}$, Hyman $\mathrm{AL}$, Ignarro $\mathrm{LJ}$, Hellstrom WJ, Kadowitz PJ. Gene transfer of endothelial nitric oxide synthase to the penis augments erectile responses in the aged rat. Proc Natl Acad Sci. USA 1999; 96(20): 11648-11652.

47. Bivalacqua TJ, Champion HC, Mehta YS, Abdel-Mageed $\mathrm{AB}$, Sikka SC, Ignarro $\mathrm{LJ}$, et al. Adenoviral gene transfer of endothelial nitric oxide synthase (eNOS) to the penis improves age-related erectile dysfunction in the rat. Int J Impot Res. 2000;12(Suppl 3):S8-17.

48. Bivalacqua TJ, Usta MF, Champion HC, Adams D, Namara DB, Abdel-Mageed AB, et al. Gene transfer of endothelial nitric oxide synthase partially restores nitric oxide synthesis and erectile function in streptozotocin diabetic rats. J Urol. 2003;169:1911-1917.

49. Christ GJ. K channels as molecular targets for the treatment of erectile dysfunction. J Androl. 2002;23(5):S1019.

50. Christ GJ, Rehman J, Day N, Salkoff L, Valcic M, Melman A, et al. Intracorporal injection of hSlo cDNA in rats produces physiologically relevant alterations in penile function. Am J Physiol. 1998;275(2 Pt 2): H600608.

51. Melman A, Zhao W, Davies KP, Bakal R, Christ GJ. The successful long-term treatment of age related erectile dysfunction with hSlo cDNA in rats in vivo. J Urol. 2003; 170:285-290.

51. bis Melman A, Bar-Chama N, Christ G, Davies K. The first phase I human gene transfer Trial: Ion channel therapy for the treatment ED - preliminary results. J Sex Med. 2004; 1(Suppl 1):14-16. 
52. Lee SW, Chae MR, Kim SH, So I. Ex vivo gene transfer of KATP channel produces physiological alterations in corporal smooth muscle cells. Int J Impot Res. 2003;15(Suppl 6):S2.

53. Chitaley K, Bivalacqua TJ, Champion HC, Usta MF, Hellstrom WJ, Mills TM, et al. Adeno-associated viral gene transfer of dominant negative RhoA enhances erectile function in rats. Biochem Biophys Res Commun. 2002; 298(3):427-432.

54. Bivalacqua TJ, Champion HC, Abdel-Mageed AB, Kadowitz PJ, Hellstrom WJ. Gene transfer of prepro-calcitonin generelated peptide restores erectile function in the aged rat. Biol Reprod. 2001;65(5):1371-1377.

55. Bivalacqua TJ, Armstrong JS, Biggerstaff J, Abdel-Mageed AB, Kadowitz PJ, Hellstrom WJ, et al. Gene transfer of

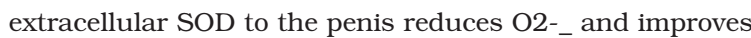
erectile function in aged rats. Am $J$ Physiol Heart Circ Physiol. 2003;284(4):H1408-1421.

56. Rogers RS, Graziottin TM, Lin CS, Kan YW, Lue TF. Intracavernosal vascular endothelial growth factor (VEGF) injection and adenoassociated virus-mediated VEGF gene therapy prevent and reverse venogenic erectile dysfunction in rats. Int J Impot Res. 2003;15(1):26-37.

57. Burchardt M, Burchardt T, Buttyan R, Anastasiadis A, De La Taille A, Shabsigh A, et al. Angiogenic factors for therapy of ED: protein and DNA transfer of VEGF in the rat penis. J Urol.2003;169(Suppl): 309-310.

58. Park K, Ahn K, Kim KK, Kim MK, Ryu SB. Effects of intracavernosal IGF-1 gene delivery on erectile function in the aging rat. Int $\mathrm{J}$ Impot Res. 2003; 15:S35.

59. Kausch I, Bohle A. Antisense oligonucleotide therapy for urologic tumors. Curr Urol Rep. 2003;4(1):60-69.

60. Kim R, Tanabe K, Emi M, Uchida Y, Toge T. Potential roles of antisense therapy in the molecular targeting of genes involved in cancer (review). Int J Oncol. 2004;24(1):5-17.

61. Bai WJ, Hou SK, Wang XF, Yan Z, He PY, Deng QP, et al. The effects of antisenes oligodeoxynucleotide on the cyclic nucleotide monophosphates in smooth muscle cells of human corpus cavernosum. Zhonghua Nan Ke Xue. 2002;8(1):88-91.
62. Jackson G, Betteridge J, Dean J, Eardley I, Hall R, Holdright $\mathrm{D}$, et al. A systematic approach to erectile dysfunction in the cardiovascular patient: a Consensus Statement-update 2002. Int J Clin Pract. 2002;56(9):663-671.

63. Montorsi P, Montorsi F, Schulman CC. Is erectile dysfunction the "tip of the iceberg" of a systemic vascular disorder? Eur Urol. 2003;44(3):352-354.

64. Champion HC, Bivalacqua TJ, Greenberg SS, Giles TD, Hyman AL, Kadowitz PJ. Adenoviral gene transfer of endothelial nitric-oxide synthase (eNOS) partially restores normal pulmonary arterial pressure in eNOS-deficient mice. Proc Natl Acad Sci. USA 2002;99(20):13248-13253.

65. Champion HC, Bivalacqua TJ, Toyoda K, Heistad DD, Hyman AL, Kadowitz PJ. In vivo gene transfer of preprocalcitonin gene-related peptide to the lung attenuates chronic hypoxia-induced pulmonary hypertension in the mouse. Circulation. 2000;101(8):923-930.

66. Bivalacqua TJ, Hyman AL, Kadowitz PJ, Paolocci N, Kass DA, Champion HC. Role of calcitonin gene-related peptide (CGRP) in chronic hypoxia-induced pulmonary hypertension in the mouse. Influence of gene transfer in vivo. Regul Pept. 2002;108(2-3):129-33.

67. Ghofrani HA, Wiedemann R, Rose F, Schermuly RT, Olschewski H, Weissmann N, et al. Sildenafil for treatment of lung fibrosis and pulmonary hypertension: a randomised controlled trial. Lancet. 2002;360(9337):895-900.

68. Kleinsasser A, Loeckinger A. Sildenafil for lung fibrosis and pulmonary hypertension. Lancet. 2003;361(9353):262263 Author reply 263.

Dr. Dirk Schultheiss

Servicio de Urologia y Urología Pediátrica

Red de Ingeniería Tisular

Facultad de Medicina de Hannover

Carl-Neuberg-Str. 1

30625 Hannover. Alemania

E-mail: schultheiss.dirk@mh-hannover.de

(Trabajo recibido el 28 febrero 2006) 